\title{
Reprogramming of Somatic Cell Identity
}

\author{
J. Hanna, * B.W. CAREY, *广 AND R. JAENisCH*广 \\ *The Whitehead Institute for Biomedical Research, Cambridge, Massachusetts 02142; \\ ${ }^{\dagger}$ Massachusetts Institute of Technology, Department of Biology, Cambridge, Massachusetts 02142
}

\begin{abstract}
All mammalian somatic cells originate from a single fertilized cell, the zygote, and share identical genetic information despite the dramatic changes in cell structure and function that accompany organismal development. The genome is subjected to a wide array of epigenetic modifications during lineage specification, a process that contributes to the implementation and maintenance of specific gene expression programs in somatic cells. Nuclear transfer and cell-fusion experiments demonstrate that the epigenetic signature directing a cell identity can be erased and modified into that of another cell type. Furthermore, in the case of cloning, differentiated cells can be reprogrammed back to pluripotency to support the reexpression of all developmental programs. Recent breakthroughs highlight the importance of transcription factors as well as epigenetic modifiers in the establishment, maintenance, and rewiring of cell identity. By focusing on reprogramming of terminally differentiated lymphocytes, we review and highlight recent insights into the molecular mechanisms and cellular events potentially underlying programming and reprogramming of somatic cell identity in mammals.
\end{abstract}

During embryonic development, pluripotent cells undergo cellular differentiation by the gradual acquisition of complex epigenetic modifications, including changes in DNA methylation and histone marks, to establish heritable gene expression programs concordant with a specific cell identity (Bernstein et al. 2007; Meissner et al. 2008). Somatic cells of the adult body are composed of both unipotent and multipotent cell types, many of which exist to support growth and repair of tissues and organs throughout the lifetime of an organism. The successful generation of animals by somatic cell nuclear transfer (SCNT) experiments in amphibians (Gurdon 1999, 2006) and subsequently mammals (Wilmut et al. 1997; Wakayama et al. 1998; Lee et al. 2005; Byrne et al. 2007) proved that cellular differentiation depends on epigenetic differences between genomes of differentiated and embryonic cells that can be reset by exposure to the oocyte cytoplasm.

For more than 20 years since the initial isolation of pluripotent embryonic stem (ES) cells, with the ability to differentiate into all cell types in vitro, many labs have used these cells to study the molecular events and genetic circuitry underlying pluripotency and cellular differentiation. In the field of regenerative medicine, ES cells have garnered much attention because the possibility of generating "patient-specific and genetically identical" ES cells by nuclear transfer holds great medical promise (Jaenisch 2004; Lerou and Daley 2005). However, technical and ethical considerations regarding the nuclear transfer procedure have hampered the application of this technique to the development of "customized" human pluripotent stem cells (Hochedlinger and Jaenisch 2006). This has stimulated efforts to better understand the molecular basis of reprogramming and to devise alternative strategies for reprogramming somatic cells to pluripotency that do not depend on nuclear transfer into oocytes. This chapter focuses on recent strategies for reprogramming somatic cells into pluripotent ES-like cells by using defined factors, with a specific focus on direct reprogramming of terminally differentiated lymphocytes as well as the use of a drug-inducible transgenic system to study the reprogramming process. We review current knowledge of potential pathways and principles underlying resetting somatic cell identity.

\section{DEFINING CELLULAR REPROGRAMMING}

Cellular reprogramming refers to the concept of rewiring the epigenetic and transcriptional network of one cell state to that of a different cell type (Egli et al. 2008). In general, reprogramming can be induced either by molecularly undefined means or by molecularly defined means (here, referred to as "direct reprogramming"). Molecularly undefined reprogramming methods, such as SCNT, fusion of somatic cells with ES cells, or explantation of cells in tissue culture, use a milieu of components or elements that are largely unknown to achieve cellular reprogramming (Fig. 1) (Hochedlinger and Jaenisch 2006; Rodolfa and Eggan 2006; Yamanaka 2008). For instance, in SCNT, undefined factors present in the oocyte cytoplasm reprogram the injected nucleus to pluripotency (e.g., transcription factors, histone-modifying and chromatin-remodeling enzymes, and DNA demethylases). In contrast, direct reprogramming methods use defined genetic or nongenetic elements to induce rewiring of the cell state. This is best illustrated by recent work describing transcription-factor-induced reprogramming of somatic cells in which defined genes are overexpressed, initiating a series of largely undefined events that eventually lead to the acquisition of a pluripotent state (Takahashi and Yamanaka 2006; Maherali et al. 2007; Takahashi et al. 
Strategies to induce epigenetic reprogramming

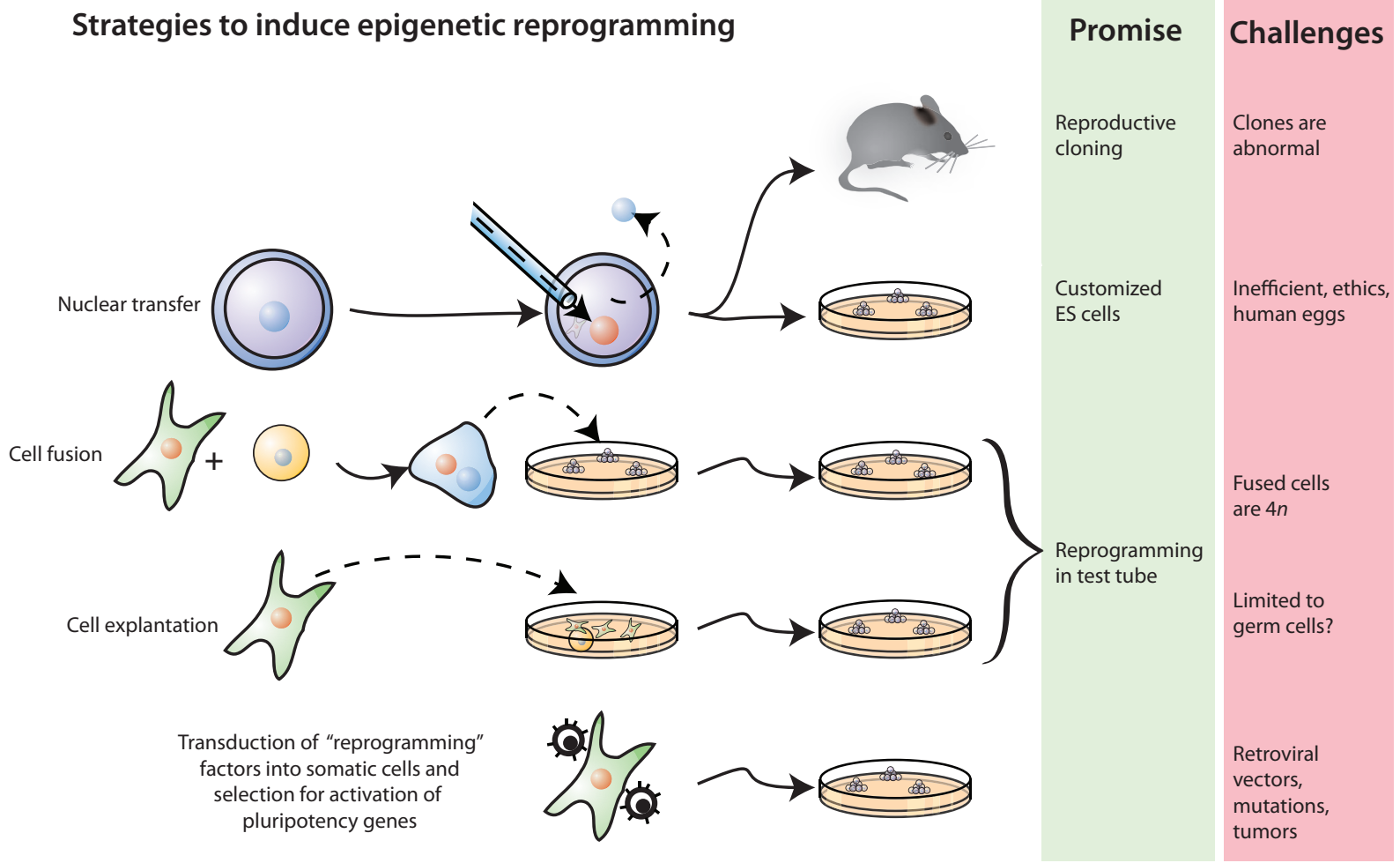

Figure 1. Methods for reprogramming somatic cells to pluripotency and schematic representation of strategies to induce reprogramming of somatic cells. Nuclear transfer involves the injection of a somatic nucleus into an enucleated oocyte, which, upon transfer into a surrogate mother, can give rise to a clone ("reproductive cloning"), or, upon explantation in culture, can give rise to genetically identical ES cells ("somatic cell nuclear transfer," SCNT). Cell fusion of ES cells with somatic cells results in the generation of hybrids and pluripotent ES-like cells. Explantation of somatic cells in culture selects for immortal cell lines that may be pluripotent or multipotent. At present, spermatogonial stem cells are the only reproducible source of pluripotent cells that can be derived from postnatal animals (Kanatsu-Shinohara et al. 2004; Guan et al. 2006; Seandel et al. 2007). Transduction of somatic cells with defined factors can initiate reprogramming to a pluripotent state and generate induced pluripotent stem (iPS) cells.

2007; Wernig et al. 2007). It should be noted that reprogramming not only encompasses dedifferentiation of somatic cells to a pluripotent ES-cell-like state, but also includes the conversion of one somatic cell type to another cell type, also referred to as "trans-differentiation." For example, Weintraub et al. (1989) have demonstrated reprogramming of fibroblasts into myoblast-like cells upon ectopic expression of the MyoD transcription factor. More recent work has shown that lineage-committed B and $\mathrm{T}$ cells can be converted into macrophage-like cells by overexpressing a myeloid transcription factor CCAAT/ enhancer-binding protein $(\mathrm{C} / \mathrm{EBP} \alpha)$ and by growth of the transduced cells in lymphoid growth-promoting cell culture conditions (Xie et al. 2004; Laiosa et al. 2006). These initial experiments were important because they paved the way for using ectopic expression of transcription factors to reprogram cells back to a pluripotent state.

\section{REPROGRAMMING SOMATIC CELLS BY MOLECULARLY UNDEFINED MECHANISMS}

Following the pioneering work of Briggs and King, John Gurdon (2006) first demonstrated that adult somatic nuclei can be reprogrammed to pluripotency when injected into enucleated oocytes. Cloned mouse blasto- cysts either can complete development in vivo and generate live adult mice or can be used to generate established ES lines in culture (Fig. 1) (Hochedlinger and Jaenisch 2006). Recent work has extended this technology to primates since the generation of blastocyst-derived pluripotent ES lines from adult somatic nuclei of rhesus macaques has been reported (Byrne et al. 2007). Despite major efforts, attempts to generate human ES cells by SCNT have so far failed, highlighting the difficulties of using nuclear transfer to generate patient-specific human ES cells. However, groundbreaking work from Eggan and colleagues demonstrates that mouse zygotes can be used as recipients in nuclear transfer (NT) experiments for somatic nuclei contingent upon temporary drug-mediated mitotic arrest of the recipient zygote (Egli et al. 2007), providing hope that discarded human in vitro fertilization (IVF)-derived zygotes could potentially be used instead of oocytes for generating human NT-ES cells. Currently, this has not been successful in humans and it is unclear whether this approach can be used to generate patient-specific ES cells.

An alternative strategy for reprogramming to pluripotency is fusion of somatic cells with mouse or human ES cells. Cell fusion has been shown to produce pluripotent hybrid tetraploid $(4 n)$ cells that have successfully reacti- 
vated key pluripotency genes as well as the inactive $\mathrm{X}$ chromosome in the somatic nucleus and can generate mature differentiated teratomas when injected in immunodeficient mice, thus providing evidence for epigenetic reprogramming of these cells (Fig. 1) (Tada et al. 2001; Cowan et al. 2005). It will be important to map the extent of reprogramming during cell fusion by genome-wide epigenetic mapping of chromatin marks of these cells in comparison to ES cells and characterize the extent of cell identity erasure that the somatic epigenome experiences upon the cell-fusion event. From a mechanistic standpoint, convincing evidence is lacking and it remains to be determined whether fusion of the nuclei and/or cell proliferation are absolute requirements for reprogramming the somatic epigenome by cell fusion or whether factors found in the ES cytoplasm would be sufficient to induce reprogramming (Jaenisch and Young 2008). Although cell fusion might prove to be useful for studying mechanisms of reprogramming, the tetraploidy of the genome in these pluripotent cells constitutes a major shortcoming of this method for generating cells that would be useful for therapy (Tada et al. 2001), because reseparating the two genomes after fusion and completion of reprogramming have not been achieved.

\section{DIRECT IN VITRO REPROGRAMMING OF SOMATIC CELLS INTO ES-LIKE CELLS BY DEFINED FACTORS}

Takahashi and Yamanaka (2006) showed that pluripotent ES-like cells can be derived from mouse fibroblast cultures upon ectopic viral transduction of the four transcription factors Oct4, Sox2, Klf4, and c-Myc, which are normally expressed in ES cells, followed by drug selection for reactivation of the Fbx15 gene (Fig. 1). Such cells, termed induced pluripotent stem (iPS) cells, were pluripotent by some criteria because they were able to form teratomas and generate early chimeric embryos. However, the initially described Fbx15 iPS cells were different from ES cells in two respects: The endogenous pluripotency genes were not fully reactivated and the pluripotent state was strictly dependent on continuous expression of the transgenic copies of Oct4 and Sox2. Moreover, Fbx15 iPS lines failed to generate postnatal chimeras, suggesting that these cells were not fully reprogrammed to pluripotency (Takahashi and Yamanaka 2006). Oct4 and Nanog gene reactivation offered a more stringent selection criteria because these proved to be functionally relevant components of the core ES cell transcriptional circuitry (Boyer et al. 2005; Jaenisch and Young 2008). Subsequent experiments introducing the same four factors into fibroblasts, followed by selection for reactivation of Oct4 and Nanog, generated fully reprogrammed iPS cells that were genetically, epigenetically, and developmentally indistinguishable from blastocyst-derived ES cells (Maherali et al. 2007; Okita et al. 2007; Wernig et al. 2007). Futhermore, iPS cells showed reactivation of the inactive $\mathrm{X}$ chromosome in female iPS lines, generated live adult chimeras with germ-line contribution, and, more stringently, generated "all iPS cell" embryos by tetrapolid complementation assay. Also, in addition to the complete demethylation and reactivation of key endogenous pluripotency factors such as Oct4 and Nanog, the ectopic viral transgenes were silenced in iPS cells (Maherali et al. 2007; Okita et al. 2007; Wernig et al. 2007), consistent with well-established evidence that Moloney viruses are efficiently silenced in pluripotent ES cells (Jahner et al. 1982). This showed that following induction of pluripotency in somatic fibroblasts, the pluripotent state can be maintained by the endogenous pluripotency circuitry. This concept was further substantiated in iPS cells induced by doxycycline (Dox)-inducible lentiviral vectors that were shown to maintain the pluripotent state independently of Dox in the culture media (Brambrink et al. 2008; Stadtfeld et al. 2008a).

Importantly, our group demonstrated that pluripotent iPS cells can be established from genetically unmodified fibroblasts without drug selection for reactivation of pluripotency genes (Meissner et al. 2007). Similarly, human iPS lines have been derived from human fibroblasts upon transduction of different combinations of reprogramming factors (Oct4, Sox2, Klf4, and c-Myc or Oct4, Sox2, Nanog, and lin28) without the need for drug selection (Takahashi et al. 2007; Yu et al. 2007; Lowry et al. 2008; Park et al. 2008b). Proof-of-principle experiments demonstrated that mouse iPS cells can be used in combined gene and cellular therapy for alleviation of diseases in vivo (Hanna et al. 2007; Wernig et al. 2008a). Finally, pluripotent lines derived from human patients with specific diseases constitute invaluable tools and an unlimited source for biological material that can be used to study these complex diseases in the Petri dish (Dimos et al. 2008; Park et al. 2008a).

\section{REPROGRAMMING OF TERMINALLY DIFFERENTIATED LYMPHOCYTES TO PLURIPOTENCY}

Calculations for reprogramming efficiency performed in various studies on mouse cells have indicated that approximately $0.01-0.1 \%$ of cells infected with all four factors are reprogrammed into iPS cells (Meissner et al. 2007; Okita et al. 2007; Wernig et al. 2007). The low reprogramming efficiency can be explained by a number of nonmutually exclusive possibilities. One possibility is that reprogrammed cells originate from rare less-differentiated cells or adult stem cells present in the donor population, a question raised in the initial cloning experiments. It was not clear whether Dolly the sheep was generated by reprogramming of a rare somatic stem cell present in the heterogeneous donor cell population, rather than a differentiated mammary gland cell as assumed, because no genetic marker was available that would allow the retrospective identification of the donor nucleus (Wilmut et al. 1997). Similarly, it could not be excluded that "adult stem cells" could have been the source for iPS lines derived from somatic fibroblast cultures, insulin-expressing pancreatic $\beta$ cells, or albumin-expressing liver cell cultures (Aoi et al. 2008; Sridharan and Plath 2008; Stadtfeld et al. 2008b). In these experiments, it is difficult to exclude that a rare stem cell, instead of a differentiated cell, was reprogrammed because no unambiguous genetic marker was used to retrospectively identify the differentiation state of 
the donor nucleus. To resolve these issues, we reprogrammed mature $\mathrm{B}$ and $\mathrm{T}$ lymphocytes and used the genetic rearrangements in the endogenous immunoglobulin or T-cell receptor (TCR) genes as markers to identify the differentiation state of the donor cell.

\section{NUCLEAR TRANSFER OF MATURE MOUSE B AND T LYMPHOCYTES}

Initial attempts to clone nuclei from mouse lymphocytes by SCNT techniques failed, suggesting that cloning these specialized cells might be impossible or highly inefficient. We therefore devised a two-step strategy to generate adult mice from mature $\mathrm{B}$ and $\mathrm{T}$ lymphocytes by first deriving ES cells from cloned blastocysts, followed by generating adult monoclonal mice using the tetraploid embryo complementation technique. Two ES lines were derived from approximately 1000 eggs injected with mature B- and T-cell nuclei. The NT-ES cell lines and the derived monoclonal mice carried rearrangements of the $\operatorname{IgH}$ and $\operatorname{IgL}$ immunoglobulin loci or TCR $\alpha$ and TCR $\beta$ chain rearrangements, demonstrating their origin from a mature B or T cell, respectively. These results provided unequivocal proof that terminally differentiated cells can be reprogrammed to a pluripotent state following exposure of the nucleus to the egg cytoplasm (Hochedlinger and Jaenisch 2002; Inoue et al. 2005). This experiment suggested that the two-step approach could overcome technical obstacles faced when cloning somatic cells. It is possible that prolonged in vitro culture of the cloned embryo in the two-step approach allowed faithful reactivation of pluripotency genes and/or selection for rare cells that acquired an ES-like phenotype. However, adult mice were derived from mature NK-T lymphocytes in a onestep cloning approach, suggesting that reprogramming these cells might be more efficient than reprogramming mature B and T cells (Inoue et al. 2005).

\section{DIRECT REPROGRAMMING OF MATURE B LYMPHOCYTES TO PLURIPOTENCY BY DEFINED FACTORS}

The ability to derive iPS cells from fibroblasts by defined factors and the success of SCNT experiments performed on mature lymphocytes to generate pluripotent lines suggested that direct reprogramming of terminally differentiated lymphocytes can, in principle, be achieved. Moreover, the hematopoietic system provides the opportunity to compare the reprogramming efficiency of cells at different stages of differentiation in the same lineage. However, the difficulty of culturing mouse lymphocytes for prolonged periods in vitro and achieving sufficiently high transduction rates of each ectopic factor constituted major obstacles to reprogramming B or T cells. To overcome these obstacles, we devised a drug-inducible transgenic system, termed "secondary system," that supports the reprogramming of multiple somatic cell types carrying identical Dox-inducible viral transgenes encoding Oct4, Sox2, Klf4, and c-Myc (Fig. 2) (Hanna et al. 2008; Wernig et al. 2008b). This was achieved by infecting fibroblasts with Dox-inducible lentiviral vectors carrying the four reprogramming factors. When cultured in the presence of Dox, multiple iPS lines were generated that could be propagated independently of Dox. As a next step, "primary" iPS lines were injected into blastocysts to generate embryonic or adult mouse chimeras, thus allowing clonal expansion and their redifferentiation into multiple somatic cells types in vivo. Because the injected iPS lines carried a constitutively expressed antibiotic resistance gene, homogeneous iPS-derived somatic cell populations such as embryonic fibroblasts, mesenchymal stem cells, neural precursors, and lymphocytes could be isolated that carried provirus integration patterns identical to those in the primary iPS cell line (Hanna et al. 2008; Wernig et al. 2008b). Cultivation of these "secondary" somatic cells in the presence of Dox efficiently generated "secondary" iPS cells, which grew independently of Dox and were shown to be pluripotent by stringent criteria (Hanna et al. 2008; Wernig et al. 2008b). Two major advantages are offered by this strategy. First, because secondary somatic cells do not require new vector-mediated factor transduction, cells that are difficult to infect can be reprogrammed. Second, the approach avoids the genetic heterogeneity produced by direct viral infection of somatic cells (Hanna et al. 2008; Wernig et al. 2008b). More recently, we have also established a secondary system for human cells (Hockemeyer et al. 2008). Human fibroblasts carrying Dox-inducible vectors encoding the human Oct4, Sox2, and Klf4 cDNAs generated secondary iPS cells with an efficiency similar to that of the mouse secondary somatic cells, which was several orders of magnitude higher than that of newly infected human fibroblasts (Meissner et al. 2007; Okita et al. 2007; Wernig et al. 2007).

Pro-, pre-, and mature B-cell populations were derived from adult "secondary" chimeras and cultured in the presence of Dox. As expected, the Oct4, Sox2, KLf4, and cMyc vectors were highly induced, but the cells failed to proliferate and most died within 5 days in culture. This suggested that initial propagation of the cells under Bcell-compatible culturing conditions might be required during the initial steps of reprogramming. Therefore, optimized culture conditions were devised to allow growth of B lymphocytes at different stages of differentiation. Cells were grown on OP9 bone marrow stromal cells in media supplemented with leukemia inhibitory factor (LIF), which is required for ES cell growth, with interleukin-7 (IL-7), stem cell factor (SCF), and Flt-3L, which promote bone-marrow-derived B-cell development (Milne et al. 2004), and with IL-4, anti-CD40, and lipopolysaccharide (LPS), which induce robust expansion of mature B cells in vitro.

Under these conditions, we were able to derive multiple iPS lines from purified pro- and pre-B-cell subpopulations that were cultured in the presence of Dox for 14 days and subsequently subcloned and cultured in normal ES cell growth conditions independent of Dox. These lines, termed iB-iPS lines (immature B-cell-derived iPS), were indistinguishable from ES cells or mouse embryonic fibroblast (MEF)-derived iPS cells, because they expressed all known pluripotency markers and generated teratomas in vivo and live adult chimeras with contribu- 


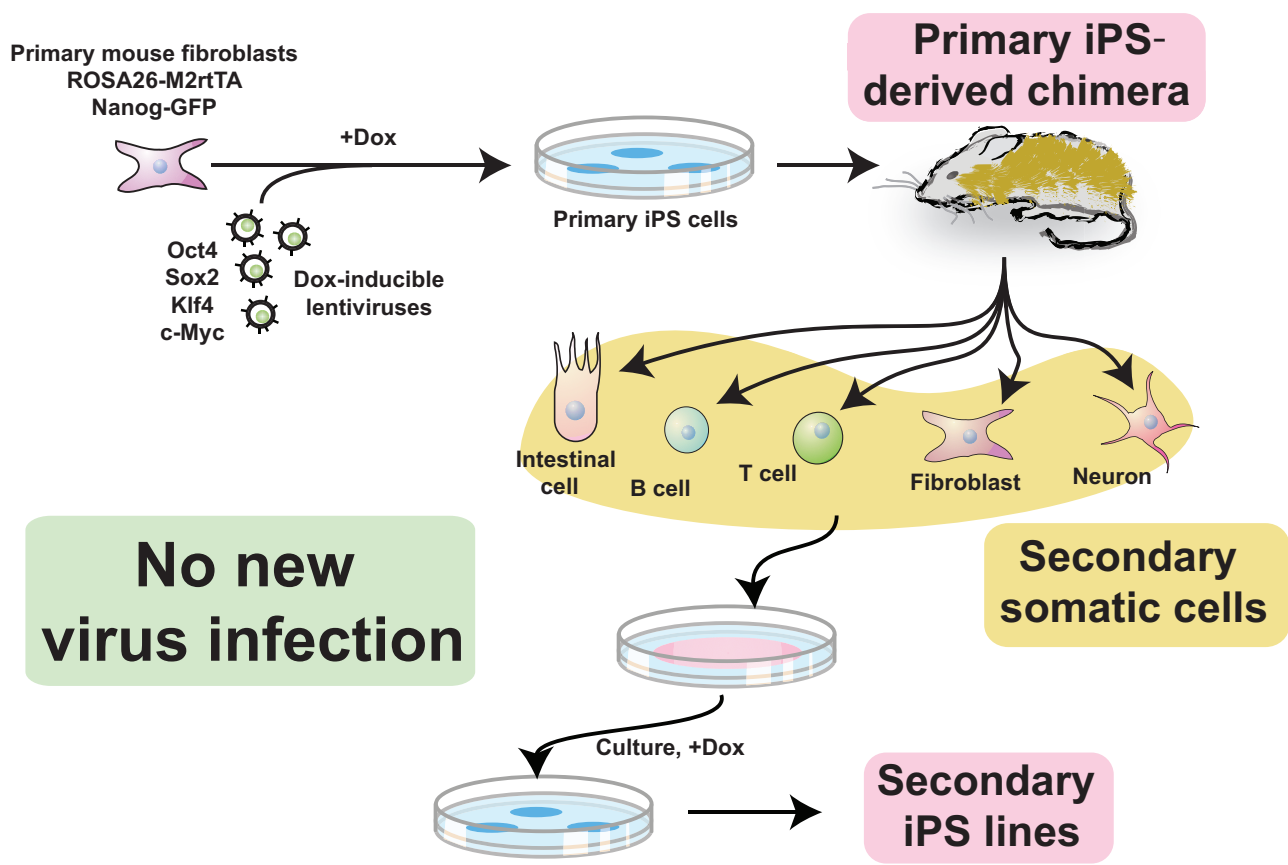

Figure 2. "Reprogrammable mouse model" for studying induction of pluripotency in homogeneous transgenic somatic cells. This mouse model constitutes an experimental system that circumvents genetic heterogeneity obtained when infecting somatic cell cultures with viruses and allows for the induction of iPS cells without requiring virus infection. In this "secondary system" strategy, primary iPS cells are generated from fibroblasts infected with Dox-inducible lentiviral vectors carrying the reprogramming factors Oct4, Sox2, Klf4, and c-Myc. Single iPS clones are injected into mouse blastocysts to generate chimeras and contribute to a variety of genetically homogeneous "secondary" somatic cells that carry the same Dox-inducible factors in their genome as their primary iPS cells. Cells from chimeric mice created using genetically reprogrammed cells can be triggered via drug administration to enter an ES-cell-like state without the need for additional direct genetic manipulation. This technical advancement enables creation of large numbers of genetically identical somatic cells that can be reprogrammed to an ES-cell-like state simply by exposure to a drug.

tions to the germ line (Hanna et al. 2008). Importantly, polymerase chain reaction (PCR) and southern blot analysis on genomic DNA obtained from iB-iPS lines demonstrated different patterns of incomplete (D-J) and complete (V-DJ) heavy-chain genetic rearrangements in the cell lines obtained, providing definitive proof that cells committed to the B-cell lineage were reprogrammed to pluripotency in our experiment.

In contrast to pro- or pre-B cells, mature B cells did not yield iPS cells when cultured in the presence of Dox. Although the cells were able to proliferate in conditioned media with Dox for a relatively extended period, no reactivation of any pluripotency-associated markers was observed, and ectopic expression of other pluripotencyrelated transcription factors did not facilitate reprogramming (Hanna et al. 2008). It appeared possible that reprogramming mature $\mathrm{B}$ cells required the disruption of the transcriptional circuitry that maintains the B-cell state. Indeed, studies by the Busslinger, Graf, and Weissman groups defined the role of Pax5, which is a transcriptional master regulator, in inducing and maintaining mature Bcell identity (Mikkola et al. 2002; Xie et al. 2004; Matthias and Rolink 2005; Delogu et al. 2006; Hsu et al. 2006; Cobaleda et al. 2007; Schebesta et al. 2007). Conditional deletion of Pax 5 in mature B cells causes loss of B-cell markers and dedifferentiation to a lymphoid pro- genitor-like state (Cobaleda et al. 2007). In vivo, these cells can be redifferentiated into the T-cell lineage. Moreover, Pax 5 null mature B cells can be differentiated into macrophages when cultured on OP-9 stromal cells under myeloid-promoting culture conditions (Mikkola et al. 2002). In addition, trans-differentiation of B cells into macrophages can be induced by transduction of the $\mathrm{C} / \mathrm{EBP} \alpha$ transcription factor, which is a major player in inducing myeloid lineage differentiation and inhibits Pax5 (Xie et al. 2004).

These observations suggested to us that interfering with the transcriptional network maintaining B-cell identity might sensitize transgenic mature B lymphocytes to overexpress Oct4, Sox2, K1f4, and c-Myc and result in robust reprogramming into pluripotent ES-like cells. Indeed, overexpression of the $\mathrm{C} / \mathrm{EBP} \alpha$ or knockdown of the Pax 5 transcription factor resulted in the efficient reprogramming of mature B cells to iPS cells upon Dox-induced vector expression (Hanna et al. 2008). The derived B-iPS cells carried at least one productive heavy-chain and light-chain rearrangement each, providing unequivocal proof that they were derived from fully differentiated adult mature B cells. The derived iPS cells were proven to be pluripotent, as evidenced by their ability to generate adult live chimeras with germ-line contribution and embryonic day 14.5 (E14.5) (4n) tetraploid chimeras (Hanna et al. 2008). The effi- 
ciency of reprogramming secondary mature B cells following additional overexpression of $\mathrm{C} / \mathrm{EBP} \alpha$ was determined to be approximately $3 \%$, similar to that of secondary embryonic or adult fibroblasts (Hanna et al. 2008; Wernig et al. 2008b). Our results suggest that reprogramming some cell types can only be achieved by sensitizing the cells to the expression of the four factors Oct4, Sox2, cMyc, and Klf4 through interfering with their somatic cell identity. Importantly, the novel drug-inducible transgenic system allowed us to gain insights into key events and principles underlying the reprogramming process, as discussed in the following section.

\section{INSIGHTS INTO THE MECHANISM OF DIRECT REPROGRAMMING}

Reprogramming the somatic epigenome to a pluripotent ES-like cell through ectopic expression of transcription factors is a process characterized by being (1) slow, (2) gradual, and (3) inefficient, with most cells in a given population ultimately failing to reprogram (Jaenisch and Young 2008). In both mouse and human fibroblast cultures, regardless of the combination of reprogramming factors used, formation of iPS cell colonies requires at least 2-3 weeks of continuous culture and proliferation (Takahashi and Yamanaka 2006; Wernig et al. 2007). It is remarkable that reprogramming terminally differentiated B lymphocytes, as well as less-differentiated neural precursor cells, occurs within a similar time frame (Eminli et al. 2008; Kim et al. 2008), arguing that the epigenetic resetting of the genome from different cell types follows similar kinetics. Unlike in SCNT experiments, where the differentiation state influences the efficiency of reprogramming (Blelloch et al. 2006), experimental evidence that somatic stem cells are easier to reprogram than differentiated by factor transduction is still lacking.

One possibility to explain the low efficiency of reprogramming is the activation of cellular genes by insertional mutagenesis. For example, proviral insertions may activate certain regulatory pathways that enhance the action of the four defined factors in resetting the epigenome. Yamanaka and colleagues (Aoi et al. 2008) failed to detect common integration sites in four iPS lines tested based on the mapping of about 20 insertion sites. However, this result does not exclude the potential role of insertional mutagenesis. For example, it may be that several alternative genes, not just one, may enhance reprogramming. It is also possible that insertional mutagenesis may not be strictly required for reprogramming but that the activation of certain cellular genes could increase the efficiency of the process.

Another possibility influencing the efficiency of reprogramming is the requirement for an optimal stoichiometry of factor expression transduced by the viral vectors. Because iPS cells carry multiple proviral copies, it may be that an optimal expression ratio of the different factors is achieved by selection for the "right" number of proviruses integrated at different chromosomal locations. Neural precursor cells, which already express the endogenous Sox2 gene, can be reprogrammed without addition of Sox2 (Eminli et al. 2008; Kim et al. 2008). Interestingly, infection with a Sox2 virus reduced the number of iPS cells, suggesting that high levels of Sox2 inhibit the reprogramming process (Eminli et al. 2008).

Reprogramming secondary somatic cells is consistent with the conclusion that the level of factor expression and/or the ratio between the expression levels of different factors may influence the efficiency of the process. Thus, Dox addition to secondary somatic cells derived from different primary iPS cells generated secondary iPS cells with efficiencies ranging from .1 \% to 4\% (Hanna et al. 2008; Wernig et al. 2008b). Because the primary iPS cells carried different and distinct proviral integrations, it is possible that those cells which were reprogrammed with high efficiency expressed the factors in a more optimal ratio than those with low reprogramming efficiency.

\section{STOCHASTIC EVENTS DURING DIRECT REPROGRAMMING}

Because secondary somatic cells are genetically homogeneous, carrying identical proviral copies, one might have expected that most if not all cells can be reprogrammed to secondary iPS cells. However, as discussed above, only a small fraction of secondary somatic cells (at best, 4\%) can be reprogrammed by Dox-induced factor activation (Hanna et al. 2008; Wernig et al. 2008b). This is consistent with the notion that stochastic epigenetic events such as demethylation of pluripotency genes or chromatin remodeling are important for the reprogramming process and restrict the fraction of cells that can ultimately be converted to secondary iPS cells. These considerations also raise the question of whether intermediate stages in the reprogramming process can be defined. Indeed, clonal cell lines that are partially reprogrammed have been recently derived from secondary fibroblasts and B lymphocytes (Meissner et al. 2007; Mikkelsen et al. 2008). These cells display a morphology different from that of iPS cells and can be extensively expanded in culture. Occasional interspersed ES-like cells grow within these cultures, which prove to be pluripotent and molecularly indistinguishable from ES cells.

Genomic analyses helped to define molecular differences between iPS cells and partially reprogrammed cells. In fully reprogrammed iPS cells, total demethylation of pluripotency genes and concurrent silencing of developmental regulators were observed, whereas only partial demethylation of pluripotency genes (e.g., Fgf4, Rex1, and GDF3) and only limited silencing of developmental regulators occurred in the partially reprogrammed cells (Mikkelsen et al. 2008). The importance of these molecular differences was underlined by the observations that DNA demethylation induced by treatment with 5Aza or knockdown of Dnmt1 facilitated complete reprogramming of the partially reprogrammed cells into iPS lines. In addition, inhibition of a single partially silenced developmental regulator such as Sox 9 or Pax7 enhanced complete reprogramming (Mikkelsen et al. 2008). Future studies aimed at defining the nature of additional secondary events that occur during reprogramming by either characterizing genetic or other epigenetic modifications that significantly increase efficiency will significantly enhance our understanding of the complex reprogramming process. 


\section{TWO SIDES OF THE SAME COIN? NUCLEAR CLONING VERSUS DIRECT REPROGRAMMING}

Reprogramming by NT sparked major interest into specific factors that could induce reprogramming of somatic nuclei. Although NT-ES cells and iPS cells have highly similar, if not identical, epigenetic and developmental potential characteristics, it is interesting to explore whether the mechanisms for inducing reprogramming by a defined factor or the oocyte cytoplasm are similar. An important observation from NT is that the key pluripotency gene Oct4 is reactivated in the somatic nucleus at the two to four cell stage in cloned embryos, suggesting that major reprogramming events can occur following one to two cell divisions (Boiani et al. 2005). In contrast, direct in vitro reprogramming of different somatic cell types proceeds during a period of at least 3 weeks in mice and even longer in humans (Fig. 3) (Jaenisch and Young 2008). These data suggest that the mechanism for reprogramming could be dramatically different. However, one cannot exclude the possibility that the oocyte cytoplasm contains a larger repertoire of reprogramming factors and therefore accomplishes reprogramming during a much shorter period. Defined transcription factor combinations can be thought of as the "minimal ingredients" recipe and most likely achieve reprogramming by induction and/or recruitment of additional targets. However, in this case, proliferation and the sequence of stochastic events may be required to make these components available. Indeed, there are a number of certain similarities in the somatic nucleus response to the four factors or oocyte cytoplasm. Both processes are highly inefficient, with most cells failing to reprogram or reactivate endogenous Oct4 and other pluripotent components. Genomic analysis studying the response of fibroblasts and $\mathrm{B}$ cells to induction of the four factors demonstrated strong up-regulation of lineage-specific genes from unrelated lineages not normally expressed in ES cells (e.g., factors required for axon guidance, renal glomerular proteins, and epidermal-specific proteins) (Mikkelsen et al. 2008). Similarly, Gurdon and colleagues observed a similar pattern for promiscuous induction of gene expression in cloned somatic nuclei in amphibians (Trendelenburg et al. 1978). These results suggest that in both reprogramming methods, molecules supporting promiscuous transcription, possibly reflecting global changes in chromatin state, may be a crucial step in mediating successful reprogramming. Although this gene activation may act as transcriptional "noise," creating a bottleneck in the activation of pluripotency circuitry (as suggested by Mikkelsen et al. 2008), it remains possible that this phenomenon is a prerequisite

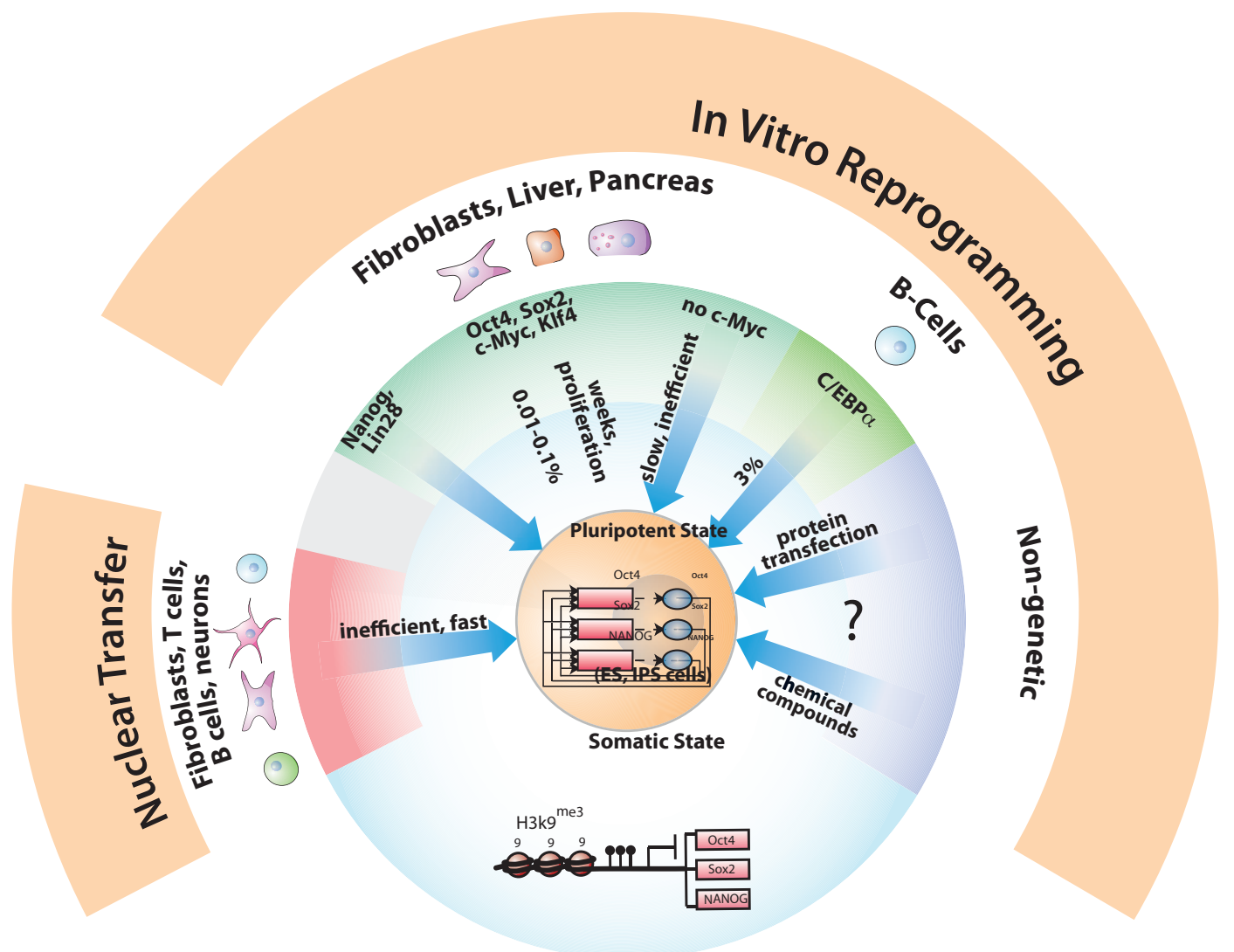

Figure 3. Reprogramming to pluripotency: past, present, and future. Shown is a schematic representation of induction of pluripotency in somatic cells by nuclear transfer and direct in vitro reprogramming. The figure highlights examples of somatic cell types used in these experiments and their efficiency and kinetics as donor nuclei for generating pluripotent ES-like cells. We also point out potential strategies that might be used in the future to generate genetically unmodified pluripotent cells in vitro. 
and precipitates the activation of specific pluripotency genes (e.g., Oct4). We predict that in the near future, many cellular events and pathways used in direct reprogramming will be unraveled, and it would be highly informative to contrast the involvement of such mediators in resetting the epigenome from different reprogramming approaches. Understanding such events will also be instrumental for devising alternative strategies to achieve safe and efficient reprogramming, i.e., by using small molecules, cytokines, or protein transfections to replace the action of some of the reprogramming factors and generate genetically unmodified iPS cells (Fig. 3).

\section{OUTLOOK}

Understanding the molecular circuitry that dictates the identity of different cell types has greatly aided our efforts toward reprogramming different somatic cells, including terminally differentiated cells, to a pluripotent state. An unresolved question is whether one somatic cell type can be converted into another cell type, without prior dedifferentiation to a pluripotent state, by direct trans-differentiation. Recently, the in vivo conversion of exocrine pancreas cells to endocrine insulin-producing cells has been achieved by expression of three transcription factors (Zhou et al. 2008). It will be a major challenge for future work to use our current knowledge of transcriptional networks active in different somatic cell types to achieve the direct reprogramming of somatic cells to cells of a different germ layer in the Petri dish.

\section{ACKNOWLEDGMENTS}

We thank L. Boyer, J. Cassady, S. Markoulaki, and members of the Jaenisch lab for excellent assistance and helpful comments. We also thank Tom DiCesare for generating illustrations. R.J. is supported by grants from the National Institutes of Health (5-RO1-HDO45022, 5-R37CA084198, and 5-RO1-CA087869). J.H. is a Novartis Fellow of the Helen Hay Whitney Foundation.

\section{REFERENCES}

Aoi, T., Yae, K., Nakagawa, M., Ichisaka, T., Okita, K., Takahashi, K., Chiba, T., and Yamanaka, S. 2008. Generation of pluripotent stem cells from adult mouse liver and stomach cells. Science 321: 699-702.

Bernstein, B.E., Meissner, A., and Lander, E.S. 2007. The mammalian epigenome. Cell 128: 669-681.

Blelloch, R., Wang, Z., Meissner, A., Pollard, S., Smith, A., and Jaenisch, R. 2006. Reprogramming efficiency following somatic cell nuclear transfer is influenced by the differentiation and methylation state of the donor nucleus. Stem Cells 24: 2007-2013.

Boiani, M., Gentile, L., Gambles, V.V., Cavaleri, F., Redi, C.A., and Schöler, H.R. 2005. Variable reprogramming of the pluripotent stem cell marker Oct4 in mouse clones: Distinct developmental potentials in different culture environments. Stem Cells 23: 1089-1104.

Boyer, L.A., Lee, T.I., Cole, M.F., Johnstone, S.E., Levine, S.S., Zucker, J.P., Guenther, M.G., Kumar, R.M., Murray, H.L., Jenner, R.G., et al. 2005. Core transcriptional regulatory circuitry in human embryonic stem cells. Cell 122: 947-956.

Brambrink, T., Foreman, R., Welstead, G.G., Lengner, C.J.,
Wernig, M., Suh, H., and Jaenisch, R. 2008. Sequential expression of pluripotency markers during direct reprogramming of mouse somatic cells. Cell Stem Cell 2: 151-159.

Byrne, J.A., Pedersen, D.A., Clepper, L.L., Nelson, M., Sanger, W.G., Gokhale, S., Wolf, D.P., and Mitalipov, S.M. 2007. Producing primate embryonic stem cells by somatic cell nuclear transfer. Nature 450: 497-502.

Cobaleda, C., Schebesta, A., Delogu, A., and Busslinger, M. 2007. Pax5: The guardian of B cell identity and function. Nat. Immunol. 8: 463-470.

Cowan, C.A., Atienza, J., Melton, D.A., and Eggan, K. 2005. Nuclear reprogramming of somatic cells after fusion with human embryonic stem cells. Science 309: 1369-1373.

Delogu, A., Schebesta, A., Sun, Q., Aschenbrenner, K., Perlot, T., and Busslinger, M. 2006. Gene repression by Pax 5 in B cells is essential for blood cell homeostasis and is reversed in plasma cells. Immunity 24: 269-281.

Dimos, J.T., Rodolfa, K.T., Niakan, K.K., Weisenthal, L.M., Mitsumoto, H., Chung, W., Croft, G.F., Saphier, G., Leibel, R., Goland, R., et al. 2008. Induced pluripotent stem cells generated from patients with ALS can be differentiated into motor neurons. Science 321: 1218-1221.

Egli, D., Rosains, J., Birkhoff, G., and Eggan, K. 2007. Developmental reprogramming after chromosome transfer into mitotic mouse zygotes. Nature 447: 679-685.

Egli, D., Birkhoff, G., and Eggan, K. 2008. Mediators of reprogramming: Transcription factors and transitions through mitosis. Nat. Rev. Mol. Cell Biol. 9: 505-516.

Eminli, S., Utikal, J.S., Arnold, K., Jaenisch, R., and Hochedlinger, K. 2008. Reprogramming of neural progenitor cells into iPS cells in the absence of exogenous Sox2 expression. Stem Cells (in press).

Guan, K., Nayernia, K., Maier, L.S., Wagner, S., Dressel, R., Lee, J.H., Nolte, J., Wolf, F., Li, M., Engel, W., and Hasenfuss, G. 2006. Pluripotency of spermatogonial stem cells from adult mouse testis. Nature 440: 1199-1203.

Gurdon, J.B. 1999. Genetic reprogramming following nuclear transplantation in Amphibia. Semin. Cell Dev. Biol. 10: 239-243.

Gurdon, J.B. 2006. From nuclear transfer to nuclear reprogramming: The reversal of cell differentiation. Annu. Rev. Cell Dev. Biol. 22: 1-22.

Hanna, J., Wernig, M., Markoulaki, S., Sun, C.W., Meissner, A., Cassady, J.P., Beard, C., Brambrink, T., Wu, L.C., Townes, T.M., et al. 2007. Treatment of sickle cell anemia mouse model with iPS cells generated from autologous skin. Science 318: 1920-1923.

Hanna, J., Markoulaki, S., Schorderet, P., Carey, B.W., Beard, C., Wernig, M., Creyghton, M.P., Steine, E.J., Cassady, J.P., Foreman, R., et al. 2008. Direct reprogramming of terminally differentiated mature B lymphocytes to pluripotency. Cell 133: 250-264.

Hochedlinger, K. and Jaenisch, R. 2002. Monoclonal mice generated by nuclear transfer from mature $\mathrm{B}$ and $\mathrm{T}$ donor cells. Nature 415: 1035-1038.

Hochedlinger, K. and Jaenisch, R. 2006. Nuclear reprogramming and pluripotency. Nature 441: 1061-1067.

Hockemeyer, D., Soldner, F., Cook, E., Gao, X., Mitalipova, M., and Jaenisch, R. 2008. A drug inducible system for direct reprogramming of human somatic cells to pluripotency. Cell Stem Cells 3: 346-353.

Hsu, C.L., King-Fleischman, A.G., Lai, A.Y., Matsumoto, Y., Weissman, I.L., and Kondo, M. 2006. Antagonistic effect of CCAAT enhancer-binding protein- $\alpha$ and Pax 5 in myeloid or lymphoid lineage choice in common lymphoid progenitors. Proc. Natl. Acad. Sci. 103: 672-677.

Inoue, K., Wakao, H., Ogonuki, N., Miki, H., Seino, K., NambuWakao, R., Noda, S., Miyoshi, H., Koseki, H., Taniguchi, M., et al. 2005. Generation of cloned mice by direct nuclear transfer from natural killer T cells. Curr. Biol. 15: 1114-1118.

Jaenisch, R. 2004. Human cloning-The science and ethics of nuclear transplantation. N. Engl. J. Med. 351: 2787-2791.

Jaenisch, R. and Young, R. 2008. Stem cells, the molecular circuitry of pluripotency and nuclear reprogramming. Cell 132: $567-582$. 
Jahner, D., Stuhlmann, H., Stewart, C.L., Harbers, K., Lohler, J., Simon, I., and Jaenisch, R. 1982. De novo methylation and expression of retroviral genomes during mouse embryogenesis. Nature 298: 623-628.

Kanatsu-Shinohara, M., Inoue, K., Lee, J., Yoshimoto, M., Ogonuki, N., Miki, H., Baba, S., Kato, T., Kazuki, Y., Toyokuni, S., et al. 2004. Generation of pluripotent stem cells from neonatal mouse testis. Cell 119: 1001-1012.

Kim, J.B., Zaehres, H., Wu, G., Gentile, L., Ko, K., Sebastiano, V., Arauzo-Bravo, M.J., Ruau, D., Han, D.W., Zenke, M., et al. 2008. Pluripotent stem cells induced from adult neural stem cells by reprogramming with two factors. Nature 454: 646650.

Laiosa, C.V., Stadtfeld, M., Xie, H., de Andres-Aguayo, L., and Graf, T. 2006. Reprogramming of committed T cell progenitors to macrophages and dendritic cells by $\mathrm{C} / \mathrm{EBP} \alpha$ and PU.1 transcription factors. Immunity 25: 731-744.

Lee, B.C., Kim, M.K., Jang, G., Oh, H.J., Yuda, F., Kim, H.J., Hossein, M.S., Kim, J.J., Kang, S.K., Schatten, G., et al. 2005. Dogs cloned from adult somatic cells. Nature 436: 641.

Lerou, P.H. and Daley, G.Q. 2005. Therapeutic potential of embryonic stem cells. Blood Rev. 19: 321-331.

Lowry, W.E., Richter, L., Yachechko, R., Pyle, A.D., Tchieu, J., Sridharan, R., Clark, A.T., and Plath, K. 2008. Generation of human induced pluripotent stem cells from dermal fibroblasts. Proc. Natl. Acad. Sci. 105: 2883-2888.

Maherali, N., Sridharan, R., Xie, W., Utikal, J., Eminli, S., Arnold, K., Stadtfeld, M., Yachechko, R., Tchieu, J., Jaenisch, R., et al. 2007. Directly reprogrammed fibroblasts show global epigenetic remodeling and widespread tissue contribution. Cell Stem Cell 1: 55-70.

Matthias, P. and Rolink, A.G. 2005. Transcriptional networks in developing and mature B cells. Nat. Rev. 5: 497-508.

Meissner, A., Wernig, M., and Jaenisch, R. 2007. Direct reprogramming of genetically unmodified fibroblasts into pluripotent stem cells. Nat. Biotechnol. 25: 1177-1181.

Meissner, A., Mikkelsen, T.S., Gu, H., Wernig, M., Hanna, J., Sivachenko, A., Zhang, X., Bernstein, B.E., Nusbaum, C., Jaffe, D.B., et al. 2008. Genome-scale DNA methylation maps of pluripotent and differentiated cells. Nature 454: 766-770.

Mikkelsen, T.S., Hanna, J., Zhang, X., Ku, M., Wernig, M., Schorderet, P., Bernstein, B.E., Jaenisch, R., Lander, E.S., and Meissner, A. 2008. Dissecting direct reprogramming through integrative genomic analysis. Nature 454: 49-55.

Mikkola, I., Heavey, B., Horcher, M., and Busslinger, M. 2002. Reversion of B cell commitment upon loss of Pax 5 expression. Science 297: 110-113.

Milne, C.D., Fleming, H.E., and Paige, C.J. 2004. IL-7 does not prevent pro-B/pre-B cell maturation to the immature/sIgM stage. Eur. J. Immunol. 34: 2647-2655.

Okita, K., Ichisaka, T., and Yamanaka, S. 2007. Generation of germline-competent induced pluripotent stem cells. Nature 448: 313-317.

Park, I.H., Arora, N., Huo, H., Maherali, N., Ahfeldt, T., Shimamura, A., Lensch, M.W., Cowan, C., Hochedlinger, K., and Daley, G.Q. 2008a. Disease-specific induced pluripotent stem cells. Cell 134: 877-886.

Park, I.H., Zhao, R., West, J.A., Yabuuchi, A., Huo, H., Ince, T.A., Lerou, P.H., Lensch, M.W., and Daley, G.Q. 2008b. Reprogramming of human somatic cells to pluripotency with defined factors. Nature 451: 141-146.

Rodolfa, K.T. and Eggan, K. 2006. A transcriptional logic for nuclear reprogramming. Cell 126: 652-655.

Schebesta, A., McManus, S., Salvagiotto, G., Delogu, A., Busslinger, G.A., and Busslinger, M. 2007. Transcription factor Pax 5 activates the chromatin of key genes involved in B cell signaling, adhesion, migration, and immune function. Immunity 27: 49-63.

Seandel, M., James, D., Shmelkov, S.V., Falciatori, I., Kim, J., Chavala, S., Scherr, D.S., Zhang, F., Torres, R., Gale, N.W., et al. 2007. Generation of functional multipotent adult stem cells from GPR $125^{+}$germline progenitors. Nature 449: 346-350.

Sridharan, R. and Plath, K. 2008. Illuminating the black box of reprogramming. Cell Stem Cell 2: 295-297.

Stadtfeld, M., Brennand, K., and Hochedlinger, K. 2008a. Reprogramming of pancreatic $\beta$ cells into induced pluripotent stem cells. Curr. Biol. 18: 890-894.

Stadtfeld, M., Maherali, N., Breault, D.T., and Hochedlinger, K. 2008b. Defining molecular cornerstones during fibroblast to iPS cell reprogramming in mouse. Cell Stem Cell 2: 230-240.

Tada, M., Takahama, Y., Abe, K., Nakatsuji, N., and Tada, T. 2001. Nuclear reprogramming of somatic cells by in vitro hybridization with ES cells. Curr. Biol. 11: 1553-1558.

Takahashi, K. and Yamanaka, S. 2006. Induction of pluripotent stem cells from mouse embryonic and adult fibroblast cultures by defined factors. Cell 126: 663-676.

Takahashi, K., Tanabe, K., Ohnuki, M., Narita, M., Ichisaka, T., Tomoda, K., and Yamanaka, S. 2007. Induction of pluripotent stem cells from adult human fibroblasts by defined factors. Cell 131: 861-872.

Trendelenburg, M.F., Zentgraf, H., Franke, W.W., and Gurdon, J.B. 1978. Transcription patterns of amplified Dytiscus genes coding for ribosomal RNA after injection into Xenopus oocyte nuclei. Proc. Natl. Acad. Sci. 75: 3791-3795.

Wakayama, T., Perry, A.C., Zuccotti, M., Johnson, K.R., and Yanagimachi, R. 1998. Full-term development of mice from enucleated oocytes injected with cumulus cell nuclei. Nature 394: 369-374

Weintraub, H., Tapscott, S.J., Davis, R.L., Thayer, M.J., Adam, M.A., Lassar, A.B., and Miller, A.D. 1989. Activation of muscle-specific genes in pigment, nerve, fat, liver, and fibroblast cell lines by forced expression of MyoD. Proc. Natl. Acad. Sci. 86: $5434-5438$.

Wernig, M., Meissner, A., Foreman, R., Brambrink, T., Ku, M., Hochedlinger, K., Bernstein, B.E., and Jaenisch, R. 2007. In vitro reprogramming of fibroblasts into a pluripotent ES-celllike state. Nature 448: 318-324.

Wernig, M., Zhao, J.P., Pruszack, J., Hedlund, E., Fu, D., Soldner, F., Broccoli, V., Constantine-Paton, M., Isacson, O., and Jaenisch, R. 2008a. Neurons derived from reprogrammed fibroblasts functionally integrate into the fetal brain and improve symptoms of adult rats with Parkinson's. Proc. Natl. Acad. Sci. 105: 5856-5861.

Wernig, M., Lengner, C.J., Hanna, J., Lodato, M.A., Steine, E., Foreman, R., Staerk, J., Markoulaki, S., and Jaenisch, R. 2008b. A drug-inducible transgenic system for direct reprogramming of multiple somatic cell types. Nat. Biotechnol. 26: 916-924.

Wilmut, I., Schnieke, A.E., McWhir, J., Kind, A.J., and Campbell, K.H. 1997. Viable offspring derived from fetal and adult mammalian cells. Nature 385: 810-813.

Xie, H., Ye, M., Feng, R., and Graf, T. 2004. Stepwise reprogramming of B cells into macrophages. Cell 117: 663-676.

Yamanaka, S. 2008. Pluripotency and nuclear reprogramming. Philos. Trans. R. Soc. Lond. B Biol. Sci. 363: 2079-2087.

Yu, J., Vodyanik, M.A., Smuga-Otto, K., Antosiewicz-Bourget, J., Frane, J.L., Tian, S., Nie, J., Jonsdottir, G.A., Ruotti, V., Stewart, R., et al. 2007. Induced pluripotent stem cell lines derived from human somatic cells. Science 318: 1917-1920.

Zhou, Q., Brown, J., Kanarek, A., Rajagopal, J., and Melton, D.A. 2008. In vivo reprogramming of adult pancreatic exocrine cells to $\beta$-cells. Nature 455: 627-632. 


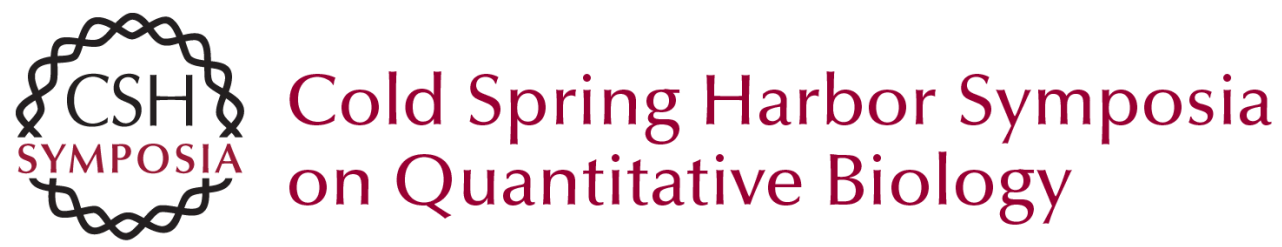

\title{
Reprogramming of Somatic Cell Identity
}

\author{
J. Hanna, B.W. Carey and R. Jaenisch
}

Cold Spring Harb Symp Quant Biol 2008 73: 147-155 originally published online November 6, 2008 Access the most recent version at doi:10.1101/sqb.2008.73.025

References This article cites 62 articles, 11 of which can be accessed free at: http://symposium.cshlp.org/content/73/147.full.html\#ref-list-1

License

Email Alerting Receive free email alerts when new articles cite this article - sign up in the box at the Service top right corner of the article or click here.

To subscribe to Cold Spring Harbor Symposia on Quantitative Biology go to: http://symposium.cshlp.org/subscriptions 